\title{
Na sombra de 1989: economia política internacional depois do fim da história
}

In the Shadow of 1989: International Political Economy after the End of History À l'ombre de 1989: économie politique internationale après la fin de l'histoire

\section{João Rodrigues}

\section{CpenEdition}

\section{Journals}

Edição electrónica

URL: http://journals.openedition.org/rccs/7834

DOI: $10.4000 /$ rccs.7834

ISSN: 2182-7435

\section{Editora}

Centro de Estudos Sociais da Universidade de Coimbra

Edição impressa

Data de publição: 7 Novembro 2018

Paginação: 189-216

ISSN: 0254-1106

Refêrencia eletrónica

João Rodrigues, « Na sombra de 1989: economia política internacional depois do fim da história », Revista Crítica de Ciências Sociais [Online], Número especial | 2018, colocado online no dia 05 novembro 2018, criado a 01 maio 2019. URL : http://journals.openedition.org/rccs/7834; DOI : $10.4000 /$ rccs. 7834 


\title{
JOÃO RODRIGUES
}

\section{Na sombra de 1989: economia política internacional depois do fim da história*}

\begin{abstract}
Quase três décadas depois de 1989, argumenta-se que continuamos a viver na sombra de um ano em que iniciaram transformações de alcance global: em termos de economia política, a crise fatal do socialismo implicou que o capitalismo, cuja viragem neoliberal se acentuou, deixou de ter freios e contrapesos sistémicos. Este diagnóstico será explorado através da escalpelização de duas fórmulas e de um documento, surgidos, talvez não por acaso, em 1989: o Consenso de Washington, o fim da história e o chamado Relatório Delors sobre a União Económica e Monetária. Vistos de forma articulada, eles refletem bem alguns dos elementos centrais de uma economia política internacional, de matriz neoliberal, ainda hoje por superar no campo institucional, devido em parte à ausência de medo entre as elites do poder. No final, em jeito de conclusão, sugere-se uma pista populista para o início da eventual superação deste perverso estado de coisas.
\end{abstract}

Palavras-chave: capitalismo; economia política; neoliberalismo; populismo; socialismo; União Europeia.

\section{Introdução}

Em 1989, com o início da queda do socialismo realmente existente, regista-se a última grande transformação na economia política internacional do "breve século xx", um período que vai da Primeira Guerra Mundial e da sua principal consequência, a Revolução Bolchevique de Outubro de 1917, até ao colapso da União Soviética, em dezembro de 1991 (Hobsbawm, 1994). Desde então, o capitalismo deixa de ter freios e contrapesos sistémicos. Estes já tinham conhecido um processo de enfraquecimento, com a crise latente

\footnotetext{
Agradeço os comentários, que muito melhoraram o artigo, de Álvaro Garrido, Ana Cordeiro Santos, António Rafael Amaro, José Reis, Paulo Coimbra, Ricardo Paes Mamede, e Sandra Monteiro, bem como as revisões de Victor Ferreira e de Sofia Silva. Este artigo beneficiou também de uma apresentação no seminário internacional "Economia Política da Crise e Reestruturação Económica: História, Dinâmicas, Implicações e Lições” realizado em outubro de 2017 no Instituto Superior de Economia e Gestão. Obviamente, todos os erros e omissões são da minha inteira responsabilidade.
} 
dos socialismos, desde meados da década de 1980. Neste contexto, reforça-se decisivamente a viragem neoliberal do capitalismo.

Assiste-se, logo no ano de 1989, ao aparecimento de duas fórmulas que refletem o espírito da época, dois sintomas intelectuais da confiança política alimentada pelos triunfos neoliberais da década de 1980: o "Consenso de Washington", ideia económica, agora convencional, apresentada nesse ano por John Williamson (1990), e "o fim da história", ideia de matriz hegeliana, reciclada em novos termos por Francis Fukuyama (1989, 1992). Deste lado do Atlântico, em Bruxelas, é apresentado, também em 1989, o Relatório sobre a União Económica e Monetária na Comunidade Europeia, vulgo Relatório Delors, sobre os passos para uma União Económica e Monetária (UEM) que seria institucionalizada na década seguinte (Comissão Europeia, 1989).

Tendo em conta esta aparente coincidência, pretendo revisitar, quase três décadas depois, estes marcos - indicando como, cada um à sua maneira $\mathrm{e}$ vistos de forma articulada, refletem bem os esteios centrais de uma forma de economia política internacional, de matriz neoliberal, que ainda hoje está por superar no campo institucional, em particular no continente europeu -, tornando-os o centro desta análise. Mais concretamente, defendo que o fim da história pode ser visto como uma profecia que se autorrealizou institucionalmente através da União Europeia (UE), inscrevendo - alguns dirão 'resgatando' - o Consenso de Washington em Bruxelas, o que de alguma forma estava previsto no Relatório Delors e foi logo confirmado pelo Tratado de Maastricht, que instituiu a União Europeia. Com a subestimada presciência que o caracteriza, Fukuyama $(1989,1992)$ apresentou a integração europeia como um dos melhores exemplos do fim da história nas relações internacionais, ou seja, das tendências inerentes à exaustão das alternativas sistémicas, e ao tipo de conflitos político-ideológicos por estas supostamente engendradas. Trata-se também de procurar novos ângulos, incluindo a ausência de medo entre as elites do poder, para aprofundar uma discussão em curso na economia política: quais as razões para a continuada resiliência do neoliberalismo, mesmo depois da sua última crise, em particular no continente europeu?

Exploro estes tópicos da história recente da economia política internacional em quatro momentos. No primeiro, exponho o argumento histórico sobre os efeitos da ausência do medo da revolução e das suas declinações em várias áreas do saber, em particular nos estudos sobre as desigualdades e nos estudos que exploram as crises do neoliberalismo, mas também as crises da social-democracia. No segundo momento, exploro o Consenso de Washington, mas também o bem menos consensual diagnóstico 
de Fukuyama, para defender que a tese de Fukuyama deve ser ainda hoje tomada bem mais a sério do que muitas vezes o foi no passado, prolongando o argumento central de Anderson (1994). No terceiro momento, invoco a crise económica mais recente, em particular nas suas declinações europeias, como um pretexto relevante para aferir a resiliência da economia política neoliberal e para explorar a ideia de que algumas das suas razões profundas mergulham nos acontecimentos intelectuais e políticos associados a 1989, um ano dito global (Lawson, 2014) e que também viu emergir o que podemos designar de Consenso de Bruxelas. Finalmente, argumento, brevemente e em jeito de conclusão, que uma forma de populismo contém potencialmente os ingredientes para uma necessária redistribuição, de baixo para cima, do medo, em particular nas periferias europeias.

\section{Medos políticos}

Numa crónica recente, Boaventura de Sousa Santos (2017) sintetiza com clareza uma tese sobre a evolução histórica recente que tem vindo a fazer o seu caminho na teoria social crítica, enquanto história racionalizada:

Os últimos anos mostraram que, com a queda do Muro de Berlim, não colapsou apenas o socialismo, colapsou também a social-democracia. Tornou-se claro que os ganhos das classes trabalhadoras das décadas anteriores tinham sido possíveis porque a URSS e a alternativa ao capitalismo existiam. Constituíam uma profunda ameaça ao capitalismo e este, por instinto de sobrevivência, fizera as concessões necessárias (tributação, regulação social) para poder garantir a sua reprodução. Quando a alternativa colapsou e, com ela, a ameaça, o capitalismo deixou de temer inimigos e voltou à sua vertigem predadora, concentradora de riqueza, armadilhado na sua pulsão para, em momentos sucessivos, criar imensa riqueza e destruir imensa riqueza, nomeadamente humana. (Santos, 2017: 23)

Nesta tese confluem três dimensões importantes para caracterizar as dinâmicas da história recente da economia política internacional. Em primeiro lugar, a constatação de que o melhor que se pode dizer das, em última instância, fracassadas experiências de socialismo realmente existente - para lá de algumas conquistas sociais internas relevantes, em particular nos campos da saúde e da educação, e de outros efeitos socioeconomicamente modernizadores e equalizadores - é que a sua existência induziu sobretudo efeitos externos positivos. Estes ter-se-iam manifestado nos países capitalistas e em certos grupos dentro desses países, em particular subalternos, que haviam conquistado direitos associados à redistribuição, mas também ao reconhecimento e à inclusão política. Assim, Losurdo $(2011,2015)$ associa 
a construção de sistemas democráticos universais e a eliminação das várias "cláusulas de exclusão" racistas, patriarcais e classistas, indissociáveis do liberalismo hegemónico no chamado longo século XIX, aos efeitos democratizadores internacionais criados pela pressão da Revolução de Outubro. Em certas circunstâncias, a combinação de mais medo entre os dominantes e de maior confiança entre os subalternos, numa nova distribuição de sentimentos com alcance político, foi propícia à emergência a prazo de um equilíbrio institucional mais favorável aos últimos. ${ }^{1}$

Em segundo lugar, a social-democracia, que tinha acabado por se tornar, em particular na Europa Ocidental, um dos agentes internos de reforma do capitalismo, acabou por ser uma vítima inesperada da queda do socialismo, a Leste. Pode aplicar-se aqui a fórmula do insuspeito Pierre Rosanvallon, associado a François Furet, um dos historiadores conservadores que mais contribuiu para destronar do imaginário social a ideia de um arco revolucionário contínuo, ligando 1789 a 1917 numa única narrativa emancipatória: "depois do colapso do comunismo, já não havia necessidade de um reformismo do medo", que tão importante teria sido para a construção dos Estados sociais capitalistas (Rosanvallon, 2016: 18). ${ }^{2}$ Não tendo sido obra exclusiva dos socialistas, a verdade é que a transformação significativa registada na fiscalidade e na gestão pública dos riscos sociais nas sociedades capitalistas, em particular na segunda metade do século XX, contou com o seu contributo decisivo. Tendo trocado a transição mais ou menos revolucionária para o socialismo pela reforma no marco do capitalismo, por via do pleno emprego e do Estado Social, algures no século Xx, a social-democracia confirmaria e reforçaria, na viragem da década de 1990, o abandono destes seus últimos compromissos, aceitando a partir daí que a palavra reforma tivesse um significado neoliberal e entrando em crise intelectual e política decisiva neste processo de abdicação. Teria, assim, existido uma

\footnotetext{
${ }^{1}$ Embora não esteja no centro das preocupações deste artigo, o qual se foca sobretudo em parte da Europa, vale ainda assim a pena referir que as lutas anticoloniais e a criação do Terceiro Mundo enquanto projeto político, associado ao que Prashad (2004) apodou de "nacionalismos internacionalistas", beneficiou direta e indiretamente da existência de um amplo bloco socialista liderado pela União Soviética depois da Segunda Guerra Mundial, mas também antes desta, com iniciativas prenunciadoras da Terceira Internacional, como o Congresso dos Povos do Oriente, em 1920, ou a fundação da Liga contra o imperialismo, em 1927. Como afirmam Best et al. (2008: 331), numa síntese convencional de história internacional do século xx: "Com a União Soviética agora vencida, os países do Terceiro Mundo viam-se impossibilitados de usar a influência do bloco comunista para tentar compensar a pressão dos EUA e dos seus aliados e vice-versa; tornaram-se, desta forma, mais vulneráveis à pressão externa do que antes". Se é verdade que existem exceções a este padrão, também é verdade que a emergência do Consenso de Washington, como se argumenta na secção seguinte, parece confirmar esta hipótese, sendo indissociável das crises dos socialismos na década de 1980 .

2 Todas as traduções são do autor.
} 
complementaridade entre social-democracia e comunismo: a crise do segundo teria levado também ao esvaziamento da primeira.

Em terceiro lugar, o contexto intelectual e político teria tornado "mais fácil imaginar o fim do mundo do que o fim do capitalismo" depois de 1989 (Jameson, 2003: 12). ${ }^{3}$ O sistema capitalista ter-se-ia tornado, de novo, praticamente universal, de tal forma que as discussões em economia política comparada se reduziram à relevância e resiliência das suas variedades e à exaltação da plasticidade do próprio capitalismo, de resto aparentemente cada vez mais uniformizado pelo neoliberalismo, em particular no Atlântico Norte. ${ }^{4}$

Neste contexto, não é de espantar que tenham aumentado significativamente as desigualdades económicas dentro dos países capitalistas centrais, ao mesmo tempo que as desigualdades entre países centrais e periféricos continuam a ser avassaladoras. Alargando o leque explicativo forjado por Piketty (2013), justamente criticado em vários quadrantes pelo facto de subestimar o papel das ideologias e das suas traduções institucionais, outro dos principais observadores quantitativos do fenómeno das desigualdades económicas, Branko Milanović, argumentou recentemente que o seu aumento inegável e generalizado nos países mais ricos a partir da década de 1980 se deveu, naturalmente entre outros fatores, ao fim do comunismo (Milanović, 2015). O efeito da presença comunista ter-se-ia manifestado na anterior compressão das desigualdades económicas de duas formas: benignamente, através da ação política dos partidos comunistas e socialistas e dos sindicatos por estes influenciados; malignamente, através do que era visto a ocidente como a ameaça político-militar soviética. Aliás, esta realidade talvez ajude a explicar que os países capitalistas europeus geograficamente mais próximos do bloco comunista, na fronteira europeia da Guerra Fria, tenham registado no pós-guerra as reduções mais significativas das desigualdades (ibidem). Em suma, "o poder político dos partidos socialistas e comunistas e o exemplo [em termos de redução das desigualdades] e ameaça militar da União Soviética travaram políticas que favoreciam os ricos mediante a limitação do poder do capital" (Milanović, 2016: 98).

Nesta linha, Streeck (2016) inscreve o crescimento das desigualdades económicas registado nos países de capitalismo maduro numa tendência

\footnotetext{
3 No quadro de uma abordagem epistémica atenta às alternativas em curso no Sul global, por muito localizadas e intersticiais que estas sejam, Boaventura de Sousa Santos opta por uma fórmula menos pessimista e mais dialética, sem deixar de reconhecer que "a queda do Muro de Berlim teve efeitos devastadores na ideia de futuros pós-capitalistas": "é tão difícil imaginar o fim do capitalismo como imaginar que o capitalismo não tenha fim” (Santos, 2014: 24).

4 Esta é a área geográfica privilegiada numa literatura de "capitalismo contra capitalismo" (Albert, 1991) ou, mais canonicamente, de variedades de capitalismo (Hall e Soskice, 2001).
} 
mais geral, em vigor desde a década de 1980, de divórcio entre sistema socioeconómico e a democracia. A hegemonia do capitalismo neoliberal teria sido temporariamente assegurada, o tempo teria sido comprado (Streeck, 2013) pela financeirização, envolvendo, entre outros aspetos, a promoção de um individualismo possessivo alimentado pelo recurso ao crédito. ${ }^{5}$ O preço deste processo tem sido a instabilidade financeira e económica crescentes, acompanhadas pelo acentuar das tendências catastróficas em matéria ambiental. Ao mesmo tempo, os Estados parecem cada vez mais impotentes democraticamente, dado que o poder do capital, com um grau de concentração e de centralização crescentes, molda as decisões políticas em regimes cada vez mais oligarquizados. O paradoxo, segundo Streeck (2016) - que o leva a uma profecia sobre um fim original do capitalismo, numa espécie de desenlace bárbaro -, encontra-se aqui: o triunfo político na Guerra Fria foi de tal ordem, enfraquecendo de tal forma os seus freios e contrapesos socialistas, que a pulsão mercadorizadora capitalista, agora irrestrita, estaria a destruir as bases não mercantis de que o próprio capitalismo historicamente dependeu para assegurar uma certa estabilidade socioeconómica e política.

Este tipo de diagnóstico, mais ou menos paradoxal, foi enunciado primeiramente pelo historiador Eric Hobsbawm e tornou-se um dos marcos das histórias críticas da economia política do século XX até aos dias de hoje (Fontana, 2017). Logo em 1990, Hobsbawm expôs um argumento sobre o "principal efeito de 1989": "o capitalismo e os ricos deixaram, até ver, de estar amedrontados" (Hobsbawm, 1990: 21). A existência de alternativas sistémicas de tipo socialista, reais ou imaginárias, na economia política internacional tinha tido como principal efeito, sobretudo no contexto histórico do seu engrandecimento depois da derrota do nazi-fascismo, a criação do tal incentivo poderoso e paradoxal para a reforma progressiva do capitalismo (Hobsbawm, 1994): a sua incrustação social e democrática em muitos espaços do Atlântico Norte teria sido um efeito indireto do medo do socialismo; a desincrustação social e democrática seria também o resultado da alteração no contexto internacional criado pelos acontecimentos de 1989.

Note-se, entretanto, que o papel atribuído por Hobsbawm à ausência de medo - anteriormente sentido pelas elites capitalistas, económicas e políticas - devido à crise dos socialismos torna saliente a importância deste

\footnotetext{
5 A identificação das tendências para a financeirização do capitalismo foi uma das áreas para as quais a economia política marxista contribuiu decisivamente, nas décadas de 1980 e 1990, mostrando de resto a sua resiliência intelectual num contexto de recuo político (Lapavitsas, 2013).
} 
sentimento, com uma declinação socioeconómica e política variada, na sua influentíssima tetralogia sobre a história do "longo século XIX" (1789-1914) e do "breve século xx" (1914-1991). Teria assim havido uma "dança dialética" entre revolução e contrarrevolução, entre dominantes e dominados, desde a Revolução Francesa; historicamente, o medo burguês teria tido consequências políticas variadas e contrastantes (Mulholland, 2012). Por vezes, o medo da revolução teria empurrado setores influentes da burguesia para o apoio a soluções politicamente autoritárias e socioeconomicamente regressivas; outras vezes, o medo da revolução teria fomentado soluções pragmáticas e progressistas. Seja como for, a chave para o influente pensamento de Hobsbawm está, no contexto histórico do fim do socialismo realmente existente, na última frase de The Age of Extremes: "o preço do fracasso, ou seja, a alternativa a uma sociedade mudada, são as trevas" (Hobsbawm, 1994: 585). ${ }^{6}$

Esta visão profundamente pessimista sobre o futuro é justificada pela constatação simultânea das contradições do capitalismo e da fraqueza das formas de ação política eventualmente capazes de o ameaçar com uma alternativa sistémica, impondo-lhe, pelo menos, mudanças nas suas formas institucionais dominantes. O que está aqui finalmente em causa é a consolidação, nas abordagens tributárias do marxismo, de uma visão da história bem menos confiante no progresso humano enquanto tendência, já que o capitalismo não só não está necessariamente prenhe do seu contrário, como o agente encarregado de fazer o parto histórico parece ter desaparecido, isto para recuperar a metáfora obstetrícia da história, criticamente formulada pelo filósofo marxista Gerald Allan Cohen (2001).

Esta visão pessimista da história, despojada de qualquer vestígio teleológico, é de resto um dos sintomas de melancolia política em tempos vistos como sombrios, em tempos que ainda estão na sombra de 1989, tendo também marcado o pensamento crítico noutros períodos de refluxo e de derrotas políticas do movimento socialista, em particular na década de 1930. A melancolia pode ser um sentimento necessário para resgatar uma certa memória perdida do socialismo, que não esqueça os seus crimes, mas também não oblitere os seus efeitos e feitos, repensando um "projeto

\footnotetext{
${ }^{6}$ Note-se que na obra do influente historiador Tony Judt, abertamente anticomunista, a defesa de uma "social-democracia do medo" se fez a partir de uma interpretação do século Xx em que o Estado-providência teria funcionado como baluarte contra as ameaças ditas totalitárias, entretanto derrotadas (Judt, 2010). Uma questão, inspirada em Eric Hobsbawm, que Judt (2009) tão denodadamente criticou pelo seu compromisso comunista, pode ser colocada neste contexto: será que um arranjo institucional redistributivo pode sobreviver com base na memória e na exaltação de virtudes morais, quando as elites do poder não são confrontadas com ameaças sistémicas, internas ou externas, no presente e no futuro previsível?
} 
revolucionário para tempos não revolucionários", tanto mais que "os fantasmas que perseguem a Europa hoje em dia não são os das revoluções do futuro, mas os das derrotadas revoluções do passado" (Traverso, 2016: 20).

Perdurando, portanto, até aos dias de hoje em grande parte da teoria social crítica, da história à economia política, esta visão contrasta vigorosamente com a confiança intelectual e política, com a crença no progresso humano, justamente sentida pelos vencedores da Guerra Fria, capazes de forjar - na viragem da década de 1980 para a de 1990 - um conjunto de diagnósticos e de propostas de política que marcaram o espírito de toda uma época no campo das ideias, que se tornam numa força material quando se inscrevem nas instituições internacionais e nacionais.

\section{Consensos ideológicos}

Em 1989, Francis Fukuyama, cientista político norte-americano, na altura funcionário do Departamento de Estado, e John Williamson, economista, na altura membro de um influente e prestigiado think-tank de Washington, o Institute for International Economics, realizaram duas intervenções intelectuais, com enorme ressonância política, devido às transformações em curso na economia política internacional. Embora não façam alusões um ao outro e tenham quadros de referência teóricos distintos - a filosofia da história de matriz neo-hegeliana e a economia convencional de matriz neoclássica, respetivamente -, a verdade é que as hipóteses do fim da história e da convergência intelectual em termos de prescrições de política económica para o desenvolvimento partem de um mesmo diagnóstico celebratório no campo das ideias, talvez só possível no "clima intelectual", para usar a expressão de Fukuyama, de fim dos combates ideológicos associados à Guerra Fria: "a total exaustão das alternativas sistemáticas viáveis ao liberalismo Ocidental" (Fukuyama, 1989: 3); "na altura [década de 1950] parecia que o socialismo era uma alternativa viável à economia de mercado; agora sabemos que não o é" (Williamson, 1993: 1331). Independentemente das querelas interpretativas a que estas duas hipóteses deram igualmente origem, estamos perante dois exemplos intelectuais complementares da confiança ideológica que irradiava do centro capitalista, politicamente triunfante, ajudando a forjar a ideia de que não existiria alternativa (There Is No Alternative - TINA), o célebre princípio neoliberal atribuído a Margaret Thatcher. Embora não usem o termo neoliberal, e até, no caso de Williamson (2004), o recusem explicitamente, a verdade é que as suas hipóteses contribuem a múltiplos níveis para a grande narrativa hegemónica num período dito de crise das grandes narrativas: de Fukuyama fica a ligação entre integração económica capitalista e democracia política como 
estádio normativo final da história, ao qual todos os países periféricos e semiperiféricos poderão vir a chegar, convergindo desta forma com um centro já "pós-histórico"; de Williamson fica um conjunto de prescrições, inicialmente pensadas tendo por referência as experiências de ajustamento estrutural dos endividados países da América Latina na década de 1980, mas rapidamente expandido à Europa Central e de Leste na década de 1990, que nos mostra a verdade de outra fórmula de Thatcher sobre a economia política neoliberal - "a economia é o método, o objetivo é mudar a alma", ou seja, tornar hegemónica a ideologia dominante através da sua inscrição mais ou menos acabada nas instituições que conduzem as políticas públicas.

Para Francis Fukuyama (1989), de forma complementar, a ideologia moldaria também o uso da economia enquanto método de transformação política, sendo aliás no campo ideológico que o laço, à escala global, entre forças de mercado na esfera económica e o demoliberalismo na esfera política teria sido primeiramente dado. Longe de corresponder ao fim dos acontecimentos, incluindo eventualmente os de grande alcance - interpretação equivocada de uma tese simultaneamente mais circunscrita e mais profunda -, Fukuyama atribui, como sublinhou Anderson (1994), a um diagnóstico relativamente consensual desses anos a dignidade de uma polémica abordagem filosófica à história: o liberalismo económico e político realmente existente, o capitalismo demoliberal, teria derrotado os seus oponentes ideológicos, em particular o socialismo, e esse triunfo sinalizaria que, ao invés de ser um mero estádio, transitório e superável, na longa marcha da história humana, seria o seu culminar no plano das ideias, sendo que são estas, em última instância, que comandam as transformações materiais. Tal seria tanto mais claro quanto o socialismo realmente existente, ao invés de ter sido um estádio superior, revelou ser um meio politicamente autoritário e economicamente ineficiente de modernização para países fora do centro do sistema mundial, tendo tido a prazo o mesmo destino histórico que outros autoritarismos reacionários de direita, mais ou menos fascistas, conheceram de forma mais precoce (Fukuyama, 1992). Nesse sentido, a vaga de transições democráticas, iniciada por Portugal na década de 1970, revelaria o verdadeiro sentido da história, mesmo que nesse caso, por um breve período, a hipótese socialista tivesse sido temporariamente real - ou não se estivesse na turbulenta década de 1970, quando ainda havia fortes razões para se ter medo da revolução entre as elites capitalistas do centro.

Escrevendo sobre "as revoluções de 1989", o eminente sociólogo histórico Krisham Kumar é certeiro sobre o paradoxo das múltiplas reações severas à tese de Fukuyama, da esquerda à direita: "provoca claramente 
irritação e raiva, mas é igualmente claro que os seus críticos têm imensas dificuldades em evitar imitá-lo, qualquer que seja a diferença dos termos usados" (Kumar, 1992: 316). Por exemplo, a única diferença, ainda que crucial, entre Fukuyama e os seus críticos socialistas mais realistas, como Eric Hobsbawm, reside na hipótese da ausência de "uma parte do mundo que credivelmente apresente uma alternativa sistémica ao capitalismo" ser um fenómeno temporário e não irreversível (Hobsbawm, 1990: 21). Para Fukuyama, as fontes de identificação política ainda populares e com resiliência - dos nacionalismos às religiões - não tinham, quase que por definição, o mesmo potencial de universalização de que dispunha agora a ideologia dominante que irradiava do centro. E isto para além de não terem o mesmo enfoque sistémico, socioeconomicamente e politicamente coerente, do que designa por "liberalismo", ainda que seja de neoliberalismo que efetivamente se trata. Isto seria tanto mais verdadeiro quanto a ideologia dominante teria plasticidade suficiente para se adaptar a vários entornos nacionais e religiosos.

Entretanto, os conflitos que eventualmente ocorreriam nos países desenvolvidos seriam acomodáveis pelas interligadas instituições fundamentais do sistema capitalista e do constitucionalismo demoliberal, aceitando Fukuyama que estas possam ter variações, ainda que de espectro estruturalmente limitado, dado que é de capitalismo que estamos e estaremos reconhecidamente a falar (Anderson, 1994). A sua distinção entre áreas históricas e pós-históricas radica precisamente num esquema evolutivo em que os países do centro mostrariam aos outros o melhor de todos os mundos possíveis. Seria na periferia e na semiperiferia do sistema mundial que a história ainda não teria acabado materialmente, dada a distância institucional em relação ao centro, embora aí nenhuma força com capacidade de oferecer uma alternativa normativamente superior à convergência com o centro pudesse expectavelmente vir a emergir (Fukuyama, 1989).

É importante, neste contexto de clarificação das teses de Fukuyama, explicitar os dois motores articulados da evolução histórica que corresponderiam à tendência para que só restasse o capitalismo demoliberal como sistema coerente e universalizável. O primeiro motor seria o da difusão do capitalismo: do ponto de vista institucional, seria o mais bem calibrado para enfrentar a complexificação crescente da divisão do trabalho a múltiplas escalas, resultante fundamentalmente da aplicação da ciência ao desenvolvimento das forças produtivas; do ponto de vista motivacional, seria capaz de canalizar o desejo e a razão dos indivíduos da esfera político-militar dos jogos de soma dita nula ou negativa para a esfera mercantil dos jogos de soma dita positiva. A acumulação e ganho material, baseados no interesse 
próprio esclarecido, supostamente pacificariam as relações sociais. O primeiro motor não seria por si só claramente suficiente: "o mundo económico moderno é uma estrutura maciça e imponente que determina ferreamente uma parte das nossas vidas, mas o seu processo de formação não esgota a história e não é suficiente para nos dizer se chegámos ao fim da história" (Fukuyama, 1992: 135). Para tal é preciso ter em atenção o segundo motor, mais político e que faz apelo a motivações humanas mais complexas, eventualmente para lá do interesse próprio, basicamente subsumidas no "desejo de reconhecimento" (ibidem).

Elaborado no seio da tradição idealista hegeliana, este complexo e poderoso desejo teria a capacidade de fazer a "ligação entre a economia liberal e a política liberal" (ibidem:206). Isso aconteceria porque os indivíduos não querem apenas enriquecer, mas querem, mais tarde ou mais cedo, ver a sua dignidade humana, a sua autonomia e liberdade reconhecidas politicamente pelos governos. Segundo Fukuyama (1992), tal só pode acontecer de forma igual e universal através das instituições políticas do demoliberalismo. No fundo, é a figura do burguês, o que apoda de classe média, cujas supostas virtudes continuam a ser elogiadas até aos dias de hoje (McCloskey, 2010), que encarnaria a articulação entre os dois motores da história.

A confiante narrativa de Fukuyama assenta num diagnóstico trivial no período em apreço, embora moldado por uma filosofia da história relativamente invulgar. Muito mais frequente é este tipo de narrativa ser moldado por uma economia política neoliberal cada vez mais vulgar. A fórmula "Consenso de Washington" teve precisamente o mérito de sistematizar essa economia política numa espécie de manifesto ou de cartilha pensada para as semiperiferias e periferias do sistema mundial pelo governo dos EUA e pelas organizações internacionais controladas, em última instância, por ele e sediadas em Washington (Fundo Monetário Internacional e Banco Mundial). Este consenso emergente, nascido da crise da dívida da década de 1980 e da sua gestão política, sobretudo nos países da América Latina, indicia que o estreitamento das opções sistémicas em curso neste período tinha a sua contrapartida no campo da política económica, mesmo no quadro do capitalismo triunfante. No entanto, e ao contrário do que muitas vezes é dito, nem o neoliberalismo, nem naturalmente o Consenso de Washington - uma das suas manifestações intelectuais e políticas mais salientes em contexto de crise, vista como uma oportunidade -, equivalem, na prática ou mesmo na teoria, a qualquer regresso a um capitalismo de laissez-faire, assente na maximização das forças de mercado e na minimização do Estado (Fine, 2001). É, aliás, a convicção equivocada de que tal seria o caso por parte de muitos dos seus críticos, como Stiglitz (2002), que parece 
justificar a previsível rejeição de tal termo por parte de Williamson (2004), ao mesmo tempo que contribui para alimentar ilusões sobre os contornos pós-neoliberais de um "consenso para lá de Washington". Clarificar o que se entende por neoliberalismo ajudará a reduzir os desencontros intelectuais registados na interpretação de dois termos interligados - neoliberalismo e Consenso de Washington - e politicamente contestados (Marangos, 2009).

Sendo o neoliberalismo, de facto, a visão hegemónica do mundo nas últimas três décadas entre as elites, e não só, as suas origens intelectuais remontam à década de 1930, começando por ser um esforço minoritário para renovar o liberalismo clássico, tentando dissociá-lo das ideias do laissez-faire e do Estado reduzido a um guarda-noturno, consideradas incapazes de fazer face aos vários "coletivismos" desglobalizadores que floresciam num contexto de crise generalizada e para lá dela, sobretudo a seguir à Segunda Guerra Mundial. A intuição central é a de que a reconstrução institucional da ordem capitalista, expurgada de muitas, mas não de todas, as concessões coletivistas entretanto feitas, terá de ser o produto de um exercício deliberado de poder político, exigindo intervenções estatais constantes para criar e manter mercados, idealmente exercidas por elites tecnocráticas protegidas da democracia. Tais intervenções passariam pela privatização de ativos, pela liberalização e regulação financeiras e comerciais conformes à expansão global dos mercados. A liberdade reconquistada de circulação de mercadorias e de capitais exerceria, por sua vez, um efeito disciplinador sobre os Estados, limitando a democracia, compelindo-os a desenhar políticas monetárias e orçamentais em consonância com os interesses das frações mais extrovertidas do capital (Mirowski, 2009; Ban, 2016). Estas frações operam através dos mercados financeiros e das suas instituições, públicas e privadas, de suporte.

No entanto, o neoliberalismo foi bem para lá destas últimas opções políticas, hegemónicas a partir da década de 1980, ou não fosse este o período em que as alternativas - mais ou menos reformistas, mais ou menos revolucionárias - ao capitalismo foram sendo fatalmente enfraquecidas, por razões internas e externas. Tratava-se, e trata-se, também de pensar um lugar para outras intervenções supletivas do Estado, capazes de corrigir eventuais falhas dos mercados em algumas áreas, mas sempre para afirmar a ideologia da concorrência mercantil. Por exemplo, na política social, tende a defender-se a substituição dos direitos sociais universais por intervenções seletivas e dirigidas, com menor impacto redistributivo; no campo da política fiscal, procura reduzir-se o peso e a progressividade dos impostos diretos, ditos ineficientes, por um alargamento da base fiscal assente sobretudo no aumento do peso na tributação dos impostos indiretos; no campo da política 
económica pode aceitar-se a política contracíclica, mas de forma limitada, na medida em que for compatível com regras políticas que a constranjam e com o funcionamento regular dos mercados financeiros; no campo da finança, o objetivo é a liberalização financeira, mas os tempos e modos desta engenharia política podem variar (Rodrigues, 2017a).

Estes exemplos servem também para chamar a atenção para o facto de o neoliberalismo ser um processo de transformação, o que justifica o facto de muitos autores preferirem falar de neoliberalização (Peck, 2010). Mas o neoliberalismo também é uma visão do mundo ambiciosa, um conjunto de ideias em perpétuo movimento político. Como qualquer projeto ideológico, admite um certo pluralismo interno, quer quanto aos métodos de análise, ao ritmo dos processos de transformação política e institucional almejados, quer quanto à escala prioritária, nacional ou supranacional, quer, mesmo, quanto a algumas das intervenções estatais necessárias, ao nível das prescrições de política pública. Em última instância, um dos elementos que confere unidade a um feixe de ideias é a natureza dos adversários intelectuais e políticos: do planeamento socialista ao keynesianismo, passando pelos modelos desenvolvimentistas. Se tomarmos esta definição abrangente, mas rigorosa, de neoliberalismo, é possível ler o Consenso de Washington e os seus avatares mais explicitamente institucionalistas - ditos "de consenso aumentado", em modo de recuperação do papel positivo do Estado - como momentos, ou fases, de um mesmo processo de incrustação diversa em várias escalas do neoliberalismo.

Se atentarmos nas dez prescrições associadas ao Consenso de Washington por Williamson (1990), é fácil concluir que as mais relevantes se inscrevem no acrónimo DLP (Desregulamentação, Liberalização e Privatização), indissociáveis do neoliberalismo, de acordo com Steger e Roy (2010), ou seja, de uma regulação estatal favorável às forças de mercado, com a abertura aos fluxos internacionais e com a privatização de empresas públicas. O próprio Williamson (1990) define as "políticas económicas que Washington prescreve ao resto do mundo" como envolvendo políticas macroeconómicas "prudentes", o que, na prática das crises de balança de pagamentos, significa austeridade, "orientação extrovertida", ou seja, inserção na globalização neoliberal e "capitalismo de mercado livre", ou seja, regras do jogo que privilegiam a liberdade dos proprietários. Para além disto, a atenção à "reforma fiscal” e a uma reorientação da despesa pública, dirigida seletivamente aos mais pobres, revela que o neoliberalismo sempre esteve associado a uma reconfiguração do Estado para o tornar mais capaz de incrustar o neoliberalismo nas várias escalas nacionais, com a ajuda, obviamente, de uma estrutura internacional de constrangimentos apropriada. 
A "convergência universal" no campo da política económica e o fim da história podem ser vistos como afirmações confiantes da superioridade ideológica e política de uma certa forma de capitalismo, só possível num contexto de triunfo sobre as suas alternativas mais ou menos sistémicas, removendo todos os vestígios de medo que as elites podiam ter sentido anteriormente.

\section{Construções institucionais: o caso do resiliente Consenso de Bruxelas}

No contexto da mais recente crise com epicentro no Atlântico Norte, iniciada em 2007-2008, muitos foram os que previram que esta seria para o neoliberalismo o que a queda do Muro de Berlim foi para o socialismo, ou seja, um momento de crise de hegemonia eventualmente irreparável (Stiglitz apud Gardels, 2008). A história poderia estar a recomeçar, como constatou Fukuyama (2012) - ainda assim perplexo com a aparente validade do diagnóstico que o tornou famoso - dada a fraqueza política das alternativas mais ou menos sistémicas no contexto da mais severa crise desde a Grande Depressão. E tanto mais que agora estava convencido da necessidade de se proceder a um maior controlo democrático da globalização para contrariar o aumento das desigualdades e os efeitos ditos iliberais da crise da classe média nas sociedades desenvolvidas. Rapidamente se constatou que a tendência político-ideológica emergente no contexto da crise económica passava pela "estranha não-morte do neoliberalismo", pela "resiliência" institucional de uma economia política que se alimentou das crises para emergir e se reforçar desde a década de 1980 (Crouch, 2011; Schmidt e Thatcher, 2013; Mirowski, 2014). Um dos espaços do sistema mundial onde tal tendência tem sido mais pronunciada é o espaço da União Europeia.

Numa análise comparada das posições tomadas e das prescrições efetuadas pelo Fundo Monetário Internacional e pelas instituições europeias - Banco Central Europeu (BCE) e Comissão Europeia (CE) - nas operações políticas conjuntas de salvação dos credores nas periferias do Leste europeu em dificuldades nas suas balanças de pagamentos, no atual contexto de crise, Lutz e Kranke (2014) constatam um maior pragmatismo na definição da condicionalidade associada ao financiamento por parte do Fundo, em contraste com uma atitude bem ortodoxa, e que acabou por prevalecer, por parte das instituições europeias. ${ }^{7}$ Neste contexto, avançam a tese de

\footnotetext{
${ }^{7} \mathrm{O}$ anúncio do pragmatismo do FMI é manifestamente exagerado. Numa análise detalhada das condições impostas em 131 países, entre 1985 e 2014, Kentikelenis et al. (2016) concluem que há um desfasamento crescente entre a retórica genérica do FMI e a de alguns dos seus economistas, que podem ir ao ponto de aceitar controlos nacionais de capitais, de criticar a austeridade ou as privatizações (Ostry et al., 2016), e as prescrições concretas do Fundo, que continuam a ser consistentes com o Consenso de Washington.
} 
que o Consenso de Washington foi "resgatado" pela UE, sendo as opções para alguns países de alargamento mais recente - que corresponderam precisamente a anteriores regimes socialistas -, uma ilustração de tal facto. Tal resgate, por sua vez, seria explicado pela continuada adesão das elites às opções de política económica permitidas pelos arranjos institucionais subjacentes ao projeto supranacional da integração económica, em geral, e ao euro, em particular (Lutz e Kranke, 2014). E estes arranjos deixaram um lastro neoliberal poderoso e difícil de reverter, como também se constatará no sul da Europa.

$\mathrm{Na}$ realidade, a adesão das elites vem de longe e esteve desde logo bem patente no Relatório Delors, publicado em 1989, sobre a lógica e os passos para a institucionalização da UEM (Comissão Europeia, 1989). Pode afirmar-se que este relatório é a versão europeia do Consenso de Washington, formulação surgida nesse mesmo ano. Ou seja, o Consenso de Bruxelas é contemporâneo do de Washington e exprime a hegemonia transatlântica do neoliberalismo.

Fukuyama (1989) afirmou que as tendências articuladas para a "economização" e para a "democratização", associadas ao triunfo ideológico irreversível do capitalismo, manifestar-se-iam, no plano internacional, na pacificação das relações entre os países da área dita pós-histórica, sendo a então "Comunidade Europeia", com o seu modelo de "mercado comum", uma das melhores encarnações institucionais dessa tendência. Na realidade, a integração europeia, desde a viragem da década de 1980 para a década de 1990, está por certo associada a tendências de "economização", ou seja, de colonização das relações políticas em várias escalas por uma certa economia em processo instituído de neoliberalização. Estas tendências seriam corporizadas através de processos substantivos de "desdemocratização", num contexto de relações internacionais mais tensas entre países fortemente integrados num sistema hierárquico com elementos imperialistas, ou seja, com elementos que facilitam a política internacional nesta área do capital financeiro (Lapavitsas, 2013). O Relatório Delors antecipa, ainda em projeto, alguns elementos da futura UEM que corroboram esta ideia.

De facto, é aí claro que o objetivo central é complementar o liberalizador mercado único em vias de ser instituído com uma moeda única, "de muitas formas uma consequência natural do compromisso com a criação um mercado sem fronteiras internas" (Comissão Europeia, 1989: 12). O programa político neoliberal de reconfiguração dos Estados é claramente enunciado, dado que, neste contexto, "de algum modo as forças de mercado podem exercer uma força disciplinadora", mas desde que reforçadas por "constrangimentos de política" desenhados explicitamente para o efeito: proibições 
de "intervenções governamentais diretas nos salários e nos preços", de "acesso ao crédito direto do banco central e a outras formas de financiamento monetário" ou a imposição de "limites aos défices orçamentais" (ibidem: 20). Estes "constrangimentos de política", onde pontifica um Banco Central dito independente e orientado para a "estabilidade de preços", transformariam os salários diretos e indiretos na variável de ajustamento principal, dado que as diferenças de competitividade entre regiões se resolveriam através de "flexibilidade salarial e de mobilidade do trabalho" (ibidem: 19), numa corrida entre modelos institucionais nacionais arbitrada, em última instância, pelas frações mais extrovertidas do capital.

Os Consensos de Washington e de Bruxelas diferem apenas porque o primeiro admite um papel para os ajustamentos cambiais na correção de desequilíbrios externos, enquanto o segundo confia no ajustamento nominal dos salários, complementado por mobilidade laboral e por algumas transferências interestaduais limitadas. Ambos exibem uma confiança no papel das forças de mercado e atribuem um papel às políticas públicas na sua crescente institucionalização. Ambos exibem uma orientação anti-keynesiana só possível porque o espectro da revolução, que teria impulsionado o projeto de tentar civilizar o capitalismo para tornar a revolução desnecessária (Mann, 2017), estava a ser claramente esconjurado ao longo da década de 1980, em claro contraste com a situação mais periclitante na década de 1970.

De facto, na década de 1970, caracterizada por uma série de bifurcações, destaca-se o diagnóstico da Comissão Trilateral, que se tornaria dominante entre as elites do poder, segundo o qual as democracias desenvolvidas estavam a ser marcadas por uma perigosa sobrecarga de exigências sociais, com rígidas traduções institucionais, que era necessário reduzir, até para recuperar o vigor económico capitalista (Monedero, 2012). Isto implicava diminuir o alcance da democracia. O diagnóstico económico da "euro-esclerose", da excessiva rigidez causada pela economia política keynesiana, pode ser reinterpretado como uma declinação geográfica específica desta análise mais geral na década de 1980. Esta "euro-esclerose" seria combatida tendo por base o que alguns denominam de "segundo projeto da integração" abertamente neoliberal (Cafruny e Reyner, 2007), do Ato Único ao euro, passando pelo Tratado de Maastricht, que proscreveu o keynesianismo no continente. Esta extinção visível na prioridade ao combate à inflação em detrimento do emprego, confirmaria o keynesianismo como equilíbrio político instável, o que foi previsto por um dos precursores intelectuais marxistas da revolução intelectual keynesiana, Michal Kalecki: o pleno emprego, atingido no capitalismo graças a uma política centrada na procura, aumentaria a confiança das classes trabalhadoras, levando-as a colocar 
em causa - como, de facto, por vezes fizeram, particularmente entre 1968 e a década de 1970 - as próprias relações de propriedade capitalistas, sendo por essa razão que os capitalistas e os seus setores intelectuais só poderiam ser, em última instância, keynesianos relutantes, compelidos por circunstâncias históricas muito específicas (Kalecki, 1943). Na década de 1980, as classes dominantes queriam um regresso da disciplina laboral que o desemprego sempre pode ajudar a criar. E, também graças ao novo arranque do projeto europeu e à crise dos socialismos, podiam olhar para o diagnóstico de Negri (1994) sobre Keynes, publicado originalmente em 1967, como parte de um legado intelectual então cada vez mais desnecessário: "Keynes foi talvez o mais penetrante teórico da reconstrução capitalista, de uma nova forma de Estado capitalista que emergiu em reação ao impacto revolucionário da classe trabalhadora de 1917" (Negri, 1994: 31).

Entretanto, o que distingue o Consenso de Bruxelas é o seu muito mais pesado lastro institucional, a intensidade da sua inscrição política, em parte função da força organizada das classes trabalhadoras nacionais a disciplinar, sobretudo a partir do Tratado de Maastricht, assinado um ano depois do fim da URSS, que institui a UE centrada no euro a partir de 1999: a direção neoliberal da integração estava então confirmada. Mais do que incompleta, como agora reconhece a sabedoria convencional, a arquitetura da UEM refletia o triunfo pleno de uma ideologia. Mais do que acreditar no fim da história como tendência espontânea, a arquitetura da UEM pretendia garantir institucionalmente que não haveria alternativa, através da mobilização de um programa hayekiano de regulação assimétrica limitador da democracia (Streeck, 2013).

De facto, os Estados democráticos abdicaram de instrumentos de política económica, a base material da soberania, condição necessária da democracia, quer porque os transferiram para instituições supranacionais com escasso ou mesmo nulo escrutínio democrático, quer porque o novo arranjo proibia a sua mobilização, quer porque os instrumentos retidos à escala nacional estavam agora muito mais condicionados pela lógica da concorrência. Esta lógica vigora à escala supranacional não apenas entre trabalhadores e empresas, mas também entre regimes sociais e fiscais. ${ }^{8}$ Quer isto dizer que as democracias à escala nacional passam a estar muito mais constrangidas, sendo que as dos países periféricos o estão mais do que as dos países centrais. Num breve ensaio, Wynne Godley, economista keynesiano britânico na tradição de Cambridge, fez, logo em 1992, um diagnóstico da economia

\footnotetext{
${ }^{8}$ A promoção desta lógica é indissociável do pensamento federalista de matriz neoliberal desde a origem - Hayek (1948), por exemplo.
} 
política que a Comissão Delors tinha realizado no decisivo Tratado de Maastricht. Vale a pena citá-lo detalhadamente:

A ideia central do Tratado de Maastricht é a de que os países da Comunidade Europeia devem avançar para a união económica e monetária, com uma moeda única gerida por um banco central independente. Mas como é que a restante política económica deve ser conduzida? Como o Tratado não propõe qualquer instituição para lá do banco europeu, os seus patrocinadores têm de presumir que nada mais seja necessário. Mas isto só seria correto se as economias modernas fossem sistemas autorregulados sem necessidade de qualquer gestão [...]. [O] poder de emitir a sua própria moeda, de recorrer ao financiamento do seu próprio banco central, é a principal dimensão da independência nacional. Se um país perde este poder é reduzido ao estatuto de uma autoridade local ou de uma colónia. As autoridades locais e regionais não podem desvalorizar, mas também não podem financiar-se através da criação monetária, enquanto os outros métodos de financiamento estão sujeitos a regulação central. [...] Se um país ou região não pode desvalorizar e se não recebe transferências orçamentais niveladoras, então nada deterá um processo cumulativo de declínio terminal, culminando, no fim, na emigração, como única alternativa à pobreza e à fome. (Godley, 1992: 3)

Este diagnóstico e prognóstico revelar-se-iam certeiros, tanto mais que dois desenvolvimentos decisivos iriam fazer sentir os seus efeitos perversos: as sucessivas rondas de alargamento da UE para os países do antigo bloco socialista, que aumentaram a heterogeneidade desta formação política supranacional em termos de desníveis de desenvolvimento, agora com mais desigualdades internas do que os EUA, mas sem mecanismos compensadores relevantes, e os choques assimétricos gerados por crises cada vez mais intensas.

Como compreender agora a força deste projeto? Em síntese, através dos mecanismos identificados, logo em 1992, pelo já referido Wynne Godley, agravados por um contexto de crise, iniciada em 2007-2008, e só com precedentes na Grande Depressão: os países periféricos têm agora o estatuto económico de semicolónias (Sapir, 2016). E isto no meio de uma crise que, segundo a teoria neoliberal na base dos arranjos da UE, não era suposto acontecer, o que diz bem da sua plausibilidade; uma crise com origens transatlânticas, ou seja, com responsabilidades partilhadas entre a UE e os EUA, mas com efeitos mais severos na primeira, já que os segundos dispunham de todos os instrumentos de um Estado soberano para reagir, evitando a repetição de 1929 de forma mais rápida. A crise foi uma crise da financeirização, ou seja, do crescimento dos motivos, mercados e agentes 
financeiros, inexplicável fora do contexto de globalização financeira e da sua cada vez mais gigantesca cadeia de dívidas e de créditos, alimentando bolhas especulativas que rebentam mais tarde ou mais cedo (Rodrigues et al., 2016). Na UE, em geral, e na Zona Euro, em particular, não foi diferente, mas o desenlace tem sido pior por razões que podem ajudar a compreender as raízes deste arranjo.

De facto, a integração económica e financeira, indissociável da UEM, manifestou-se primordialmente no afluxo de capitais, sob a forma crédito, para as mais atrativas periferias europeias, em termos de rendibilidade potencial, devido também à atenuação ou ao desaparecimento do risco cambial. Trancadas numa moeda forte, ou a esta ligadas, sem instrumentos de política, as periferias tenderam a acumular défices de balança corrente e uma dívida externa em euros, as contrapartidas necessárias do recebimento de crédito. Do outro lado do que foi e é uma relação social internacional, o centro europeu, em especial os bancos alemães, acumularam créditos, um fenómeno indissociável dos superávites de balança corrente da Alemanha.

Emergiu, então, um padrão devedor-credor no contexto de uma moeda que, na perspetiva dos devedores, era estrangeira, ou seja, não era controlada pelos seus bancos centrais (Rodrigues et al., 2016). Com variedades de capitalismo distintas, com países em diferentes níveis de desenvolvimento, mas partilhando o mesmo espaço de integração, este padrão é a expressão financeira de relações cada vez mais assimétricas. Com o desencadear da crise e o inevitável aumento dos défices públicos, a periferia foi colocada numa posição insustentável, dependendo dos mercados financeiros em pânico para se refinanciar, já que os países tinham prescindido dos seus bancos centrais e o BCE estava proibido de emprestar aos Estados. Sem poderem desvalorizar as moedas, sem bancos centrais próprios, as periferias, incluindo Portugal, ficaram sujeitas a ver a história a ser escrita pelos credores e pelos seus interesses. Foi, então, montada uma operação de salvamento público dos bancos privados do centro europeu, altamente implicados na periferia, através do financiamento oficial dos Estados em dificuldades. Surge neste contexto a troika - FMI, BCE e CE -, ou seja, a confirmação de que o Consenso de Washington, o da austeridade e da neoliberalização, mais do que ter sido resgatado pela integração europeia, teve a sua versão em Bruxelas desde 1989. As políticas de austeridade e de neoliberalização regressaram em força na segunda década do novo milénio e com uma lógica particularmente punitiva, transferindo os custos sociais da crise para as classes subalternas. Estamos em condições de explicar então melhor esta sobrevivência, e até eventual reforço, dos processos de neoliberalização? 
Em primeiro lugar, o lastro institucional deixado pelo neoliberalismo antes da crise constitui parte da explicação. Sem instrumentos de política económica, a democracia política é impotente para gerar alternativas reais na escala onde pode existir. Os povos veem-se literalmente "gregos". De facto, confrontado com uma crise só com paralelo na Grande Depressão, igualmente associada a estruturas de integração perversas, o povo grego, por exemplo, elegeu um governo com um programa vincadamente antineoliberal. Recusando romper com o quadro institucional europeu, em particular com o euro, o governo grego acabou por ser anulado por um golpe financeiro protagonizado pelas instituições europeias, acabando a implementar as políticas neoliberais ditadas pelos credores europeus (Rodrigues, 2017a). Entretanto, as operações do BCE, no campo monetário, e um momento anterior, breve e abastardado, de política orçamental contracíclica, demasiado centrado nos bancos, são o keynesianismo possível entre as elites europeias face ao receio de alastramento da crise no centro, mas não face à força de alternativas políticas cooptáveis.

Em segundo lugar, e em articulação com o lastro institucional, vem o lastro ideológico. A verdade é que uma parte das supostas forças intelectuais e políticas críticas e alternativas ao neoliberalismo acabou por aceitar como boas muitas das suas hipóteses, desde o final da década de 1980, em parte como reação à derrota das alternativas socialistas. Tal é o caso das que se referem à irreversibilidade da globalização e das suas expressões no continente por via de uma integração europeia politicamente blindada, mas ainda assim muito idealizada; tal é também o caso das que se referem à aceitação de uma lógica binária, construída para manter a hegemonia neoliberal: integração económica liberal plena ou autarcia económica liberticida. Vivemos definitivamente, no continente europeu, na sombra de 1989. O globalismo - a falta de confiança no aproveitamento das oportunidades nacionais que advêm potencialmente da conquista do poder de Estado e da mobilização de instrumentos de política para gerir o grau de abertura económica - é uma das suas consequências.

\section{Conclusão e reinício da história: o espectro do populismo}

Em 1990, Eric Hobsbawm assinalava que o espectro do socialismo tinha desaparecido do horizonte no futuro previsível devido aos acontecimentos de 1989. Fukuyama havia já anunciado o fim da história, tese reforçada em 1992.9 Tinha sido, em parte, o medo do socialismo a alimentar a reforma social e democrática do capitalismo, em particular a seguir à Segunda Guerra Mundial.

\footnotetext{
${ }^{9}$ Esta conclusão retoma os termos primeiramente ensaiados em Rodrigues (2017b).
} 
Num contexto em que o neoliberalismo tem sabido durar, há uma questão que se impõe: na ausência de um campo socialista, o que é que pode hoje causar medo à elite económica e política dominante, que beneficiou de uma globalização entretanto acelerada pela ação das instituições supranacionais, incluindo a União Europeia - talvez a mais poderosa máquina institucional de liberalização económica? A resposta talvez passe por uma variante do populismo, capaz de unificar os vários descontentamentos e os justos ressentimentos. E esta tem de ter uma orientação eurocética, ou seja, radicalmente crítica da UE realmente existente. E isto se se quiser superar o lastro institucional responsável pela estreiteza das alternativas, desprovidas de qualquer alcance sistémico ou, mesmo, pela total ausência de alternativas.

Valorizar a resposta populista exige confrontar os hábitos de pensamento dos que, tendo abandonado o terreno da economia política crítica, falam de populismo, mas também de nacionalismo, cada um no singular, reduzindo-os a discursos étnicos e culturais perversos e manipulatórios, como se fossem muitas vezes desprovidos de razões ou ancoragens materiais. No fundo, "populismo é o termo que as elites usam para as políticas de que não gostam, mas que a gente comum apoia” (Fukuyama, 2016: 68). O populismo que emerge é o nome de um novo espectro que mete medo e que importa uniformemente esconjurar, na ótica das elites do poder. $\mathrm{Na}$ ótica dos subalternos, o populismo pode ser o nome possível para, tomando de empréstimo os termos de Polanyi (2012 [1944]), um contramovimento multiforme de proteção das sociedades nacionais em relação às múltiplas crises geradas pela finança e pelas suas expressões institucionais internacionais, um meio para, através de um impulso economicamente desglobalizador, eventualmente voltar a encarar a questão do socialismo, saindo da sombra de 1989.

É preciso, entretanto, precisar que populismos, tal como nacionalismos, existiram e existirão sempre muitos, antagónicos nas suas justificações e nas suas consequências. Centrado no Atlântico Norte e em contracorrente com uma literatura de combate, Judis (2016) distingue o populismo "triádico" e o populismo "diádico". O populismo dito triádico, de Donald Trump a Marine Le Pen, alimenta uma clivagem, sobretudo cultural, entre povo e elite, sendo que esta última é acusada de proteger um terceiro grupo, minoritário, que serve então de bode expiatório para problemas reais. O populismo diádico, de Bernie Sanders a Jean-Luc Mélenchon ou Jeremy Corbyn, expõe politicamente uma clivagem material, bem real, entre povo e elite, resultado de décadas de regras neoliberais que transferem recursos de baixo para cima e medo de cima para baixo, decisivamente favorecidas pela globalização. 
A força dos populismos é totalmente incompreensível sem as crises recorrentes da globalização e da financeirização em sociedades cada vez mais desiguais e fragmentadas, onde a polarização social facilita politicamente a emergência de uma clivagem entre um "nós" e um "eles". Como defendeu o teórico político Ernesto Laclau (2013), tal clivagem, essa "fronteira de antagonismo", é, em última instância, indissociável de sociedades onde as massas muito dificilmente podem ser totalmente arredadas da política, apesar de todos os esforços elitistas e pós-democráticos tão visíveis na UE.

No entanto, se é verdade que essa fronteira é uma criação discursiva de uma identidade política, também é verdade que esta tem de partir, para ser bem-sucedida, de uma análise que não ignore as dinâmicas da economia política. Se atentarmos na análise de Rodrik (2017), o populismo triádico seria favorecido, neste contexto, pela saliência política dos fluxos migratórios, enquanto o diádico seria favorecido pela saliência política dos fluxos comerciais e financeiros internacionais. Os fluxos são variados e as desglobalizações potencialmente também. Estamos agora muito longe do otimismo evidenciado pelas elites intelectuais neoliberais do final da década de 1980 . O próprio Fukuyama (2012), ao mesmo tempo que reafirma a validade das suas teses sobre o fim da história, fez recentemente um diagnóstico bem menos otimista, de alguma forma reconhecendo a necessidade de, pelo menos, colocar freios democráticos mais capazes ao capitalismo, o que passa por conter a globalização.

Para além de ser um contraponto útil a um populismo triádico complementar ao neoliberalismo e que canaliza a justificada raiva e angústia populares para os que estão ainda mais em baixo, a promessa que o populismo diádico encerra para a gente comum é a de colocar o enfoque numa redistribuição modificada por transformações nas formas da economia política: finalmente, o medo deve poder fluir de baixo para cima e os recursos de cima para baixo. Para tal, é necessário limitar a política de fronteiras totalmente abertas que alimenta todas as chantagens que dão poder às frações do capital com maior mobilidade na UE. Sem algum grau de fronteira económica, sem controlo político democrático sobre os capitais e sobre os fluxos comerciais ao nível dos Estados, não há responsabilidade política democrática; nem forma de segurança defensável, a social, a que é garantida pela provisão pública de recursos essenciais. A política popular passou sempre pela disputa ideológica das formas de fronteira e de segurança a garantir. Desertar intelectual e politicamente deste terreno, aceitando a narrativa neoliberal sobre a irreversibilidade das estruturas de integração, implica entregá-lo à perversa imaginação do populismo triádico. 
Entretanto, e isto vale ainda mais para as periferias do que para o centro europeu, o discurso populista diádico não pode cingir-se à redistribuição, já que tem de colocar o problema do desenvolvimento das capacidades socioeconómicas nacionais; ou seja, o populismo tem de ser desenvolvimentista, cuidando neste processo de uma distribuição primária do rendimento mais equilibrada, produto de relações de poder mais favoráveis à grande massa dos trabalhadores. É também por isto que o populismo tem de ser civicamente nacionalista e, por conseguinte, eurocético. É porque é muito difícil imaginar formas de desenvolvimento conduzidas a partir de fora da comunidade política que tal ainda é mais relevante. $\mathrm{O}$ desenvolvimento parece, de facto, pressupor um controlo nacional de instrumentos de política pública que garantam alguma margem de manobra aos Estados para protegerem e modificarem as instituições nacionais, tornando-as mais inclusivas. Do Serviço Nacional de Saúde ao Salário Mínimo Nacional, passando pela reconstrução de setores económicos estratégicos e que devem ser nacionalizados, pelo reforço da contratação coletiva nacionalmente centralizada ou por prestações sociais decentes e universais, são estas instituições que dão densidade material a uma primeira pessoa do plural, o tal nós sem o qual não há política democrática. Este plural também se alimenta de uma sociedade com emprego decente para todos. Tal objetivo, que muda decisivamente a correlação das forças sociais, historicamente também só foi possível com a mobilização de instrumentos de política económica hoje bloqueados pela integração e tanto mais necessários em Estados de pequena dimensão e que querem encontrar nichos favoráveis num mundo multipolar, garantindo, em simultâneo, o equilíbrio externo, ou seja, cortando com a dependência perversa da poupança externa. Como o caso islandês, entre outros, em certa medida ilustra, tal é ainda possível no presente, da mesma maneira como o foi, de forma ainda mais óbvia, num passado não muito distante.

$\mathrm{Na}$ periferia europeia, onde as dinâmicas internas são hoje sobredeterminadas externamente, a construção de uma vontade nacional-popular tem um elemento diádico, contra uma elite nacional com elementos plutocráticas, que age e pensa como se estivesse no centro. Mas também tem um elemento triádico, embora modificado, na medida em que, da dívida denominada numa moeda que o país não controla ao controlo estrangeiro da banca, passando pelo euro, aquela elite depende de um terceiro elemento externo: não o imigrante, claro, mas, sim, a finança do Norte e as suas expressões político-institucionais europeias. No continente europeu, a força dos populismos que merecem ser defendidos implica colocar o desmantelamento, se possível coordenado, da Zona Euro em cima da mesa, não faltando propostas neste sentido (Flassbeck e Lapavitsas, 2015). Para além 
de ser necessário para garantir o financiamento numa moeda que se controla democraticamente e cujo valor pode ser gerido, este desmantelamento é, de resto, uma decorrência da reestruturação da dívida necessária por iniciativa dos países devedores e da imposição de formas de controlos de capitais e da banca que os protejam contra as principais formas de instabilidade financeira. O caso da Grécia ilustra o que acontece às alternativas políticas em países sem instrumentos de política.

No fundo, e como nos lembra Polanyi, é da "desagregação de uma economia de mercado [institucionalmente] uniforme" (2012 [1944]: 465) que podem nascer as alternativas, aumentando as possibilidades de autodeterminação coletiva e de formas de cooperação internacional funcionais, aumentando as possibilidades de fazer e refazer a História.

Neste contexto, é tempo de se atentar, em simultâneo, nas potencialidades do vínculo nacional e popular e nos custos em termos de desenvolvimento que se pagam quando o controlo estrangeiro dos recursos passa um certo limiar. Apesar de todos os esforços intelectuais, partindo das margens para o centro, o espectro populista não se esconjura hoje facilmente. Há boas razões materiais e intelectuais para tal. Em democracia, mesmo que limitada, o medo pode estar concentrado em baixo por quanto tempo?

Revisto por Sofia Silva

\section{Referências bibliográficas}

Albert, Michel (1991), Capitalisme contre capitalisme: Paris: Seuil.

Anderson, Perry (1994), Los fines de la historia. Barcelona: Anagrama.

Ban, Cornel (2016), Ruling Ideas - How Global Neoliberalism Goes Local. Oxford: Oxford University Press.

Best, Antony; Hanhimäki, Jussi; Maiolo, Joseph; Schulze, Kirsten (2008), International History of the Twentieth Century and Beyond. London: Routledge.

Cafruny, Alan; Ryner, Magnus (2007), Europe at Bay: In the Shadow of US Hegemony. Boulder, CO: Rienner.

Cohen, Gerald (2001), If You're an Egalitarian, How Come You're So Rich? Cambridge, MA: Harvard University Press.

Comissão Europeia (1989), Report on Economic and Monetary Union in the European Community. Luxembourg: Office for Official Publications of the European Communities. Crouch, Colin (2011), The Strange Non-Death of Neoliberalism. Cambridge: Polity. Fine, Ben (2001), "Neither the Washington nor the Post-Washington Consensus”, in Ben Fine; Costas Lapavitsas; Jonathan Pincus (orgs.), Development Policy in the Twenty-First Century: Beyond the Post-Washington Consensus. London: Routledge, 1-27. 
Flassbeck, Heiner; Lapavitsas, Costas (2015), Against the Troika. London: Verso.

Fontana, Josep (2017), El siglo de la revolución. Barcelona: Critica.

Fukuyama, Francis (1989), “The End of History?”, The National Interest, Summer, 3-18.

Fukuyama, Francis (1992), The End of History and the Last Man. London: Penguin.

Fukuyama, Francis (2012), "The Future of History: Can Liberal Democracy Survive the Decline of the Middle Class?”, Foreign Affairs, 91(1), 53-61.

Fukuyama, Francis (2016), "American Political Decay or Renewal? The Meaning of the 2016 Election”, Foreign Affairs, 95(4), 58-68.

Gardels, Nathan (2008), "Stiglitz: The Fall of Wall Street Is to Market Fundamentalism What the Fall of the Berlin Wall Was to Communism”, Huffington Post, de 17 de outubro. Consultado a 02.11.2017, em http://www.huffingtonpost.com/nathan-gardels/stiglitz-the-fall-of-wall_b_126911.html.

Godley, Wyne (1992), "Maastricht and All That", London Review of Books, 14(19), 3-4.

Hall, Peter; Soskice, David (orgs.) (2001), Varieties of Capitalism: The Institutional Foundations of Comparative Advantage. Oxford: Oxford University Press.

Hayek, Friedrich (1948), "The Economic Conditions of Interstate Federalism”, Individualism and Economic Order. Chicago: The University of Chicago Press, 255-272.

Hobsbawm, Eric (1990), "Goodbye to All That”, Marxism Today, Outubro, 18-23.

Hobsbawm, Eric (1994), The Age of Extremes - The Short Twentieth Century 1914-1991. London: Michael Joseph.

Jameson, Frederic (2003), "Future City", New Left Review, 21, 65-79.

Judis, John (2016), The Populist Explosion. New York: Columbia University Press.

Judt, Tony (2009), "Eric Hobsbawm and the Romance of Communism", Reappraisals: Reflections of the Forgotten Twentieth Century. New York: Penguin, 116-128.

Judt, Tony (2010), Ill Fares the Land. London: Penguin.

Kalecki, Michal (1943), "Political Aspects of Full Employment", Political Quarterly, 14(4), 322-330. DOI: https://doi.org/10.1111/j.1467-923X.1943.tb01016.x.

Kentikelenis, Alexander; Stubbs, Thomas; King, Lawrence (2016), "IMF Conditionality and Development Space, 1985-2014", Review of International Political Economy, 23(4), 543-582. DOI: https://doi.org/10.1080/09692290.2016.1174953.

Kumar, Krisham (1992), "The Revolutions of 1989: Socialism, Capitalism, and Democracy”, Theory and Society, 21(3), 309-356. DOI: https://doi.org/10.1007/ BF00993452.

Laclau, Ernesto (2013), On Populist Reason. London: Verso.

Lapavitsas, Costas (2013), Profiting Without Producing: How Finance Exploits Us All. London: Verso.

Lawson, George (2014), “Introduction: The 'What', 'When' and 'Where' of the Global 1989”, in George Lawson; Chris Armbruster; Michael Cox (orgs.), The Global 1989. Cambridge: Cambridge University Press, 1-20.

Losurdo, Domenico (2011), Liberalism: A Counter-History. London: Verso. 
Losurdo, Domenico (2015), War and Revolution: Retbinking the Twentieth Century. London: Verso.

Lutz, Susanne; Kranke, Matthias (2014), "The European Rescue of the Washington Consensus? EU and IMF Lending to Central and Eastern European Countries”, Review of International Political Economy, 21(2), 310-338. DOI: https://doi.org/ 10.1080/09692290.2012.747104.

Mann, Geoff (2017), In the Long Run We Are All Dead: Keynesianism, Political Economy and Revolution. London: Verso.

Marangos, John (2009), "What Happened to the Washington Consensus? The Evolution of International Development Policy”, Journal of Socio-Economics, 38(1), 197-208. DOI: https://doi.org/10.1016/j.socec.2008.07.007.

McCloskey, Deirdre (2010), Bourgeois Dignity: Why Economics Can't Explain the Modern World. Chicago: University of Chicago Press.

Milanović, Branko (2015), "Did Socialism Keep Capitalism Equal?”, Social Europe, de 27 de agosto. Consultado a 20.07.2017, em https://www.socialeurope.eu/ did-socialism-keep-capitalism-equal.

Milanović, Branko (2016), A desigualdade no mundo: uma nova abordagem para a era da globalização. Lisboa: Actual.

Mirowski, Philip (2009), “Postface: Defining Neoliberalism”, in Philip Mirowski; Dietre Plehwe (orgs.), The Road from Mont Pelerin - The Making of the Neoliberal Thought Collective. Cambridge, MA: Harvard University Press, 417-455.

Mirowski, Philip (2014), Never Let a Serious Crisis Go to Waste: How Neoliberalism Survived the Financial Meltdown. London: Verso.

Monedero, Juan Carlos (2012), "El programa de máximos del neoliberalismo: el Informe a la Trilateral de 1975", Sociologia Historica, 1, 289-310. Consultado a 03.11.2017, em http://revistas.um.es/sh/article/view/165231.

Mulholland, Marc (2012), Bourgeois Liberty and the Politics of Fear: From Absolutism to Neo-Conservatism. Oxford: Oxford University Press.

Negri, Antonio (1994), "Keynes and the Capitalist Theory of the State", in Michael Hardt; Antonio Negri (orgs.), Labor of Dionysus: A Critique of State Form. Minneapolis, MN: University of Minnesota Press, 23-51.

Ostry, Jonathan; Loungani, Prakash; Furceri, Davide (2016), “Neoliberalism: Oversold?", Finance \& Development, 53(2), 38-41.

Peck, Jamie (2010), Constructions of Neoliberal Reason. Oxford: Oxford University Press. Piketty, Thomas (2013), Le capital au 21e siècle. Paris: Seuil.

Polanyi, Karl (2012), A grande transformação. Lisboa: Edições 70 [orig. 1944].

Prashad, Vijay (2004), The Poorer Nations. A Possible History of the Global South. London: Verso.

Rodrigues, João (2017a), “O neoliberalismo não é um slogan”, in VV. AA., Economia com todos. Lisboa: Relógio D’Água, 15-32. 
Rodrigues, João (2017b), “Em defesa de um populismo”, jornal Público, de 1 de setembro. Consultado a 05.11.2017, em https://www.publico.pt/2017/09/01/politica/ opiniao/em-defesa-de-um-populismo-1783959.

Rodrigues, João; Santos, Ana Cordeiro; Teles, Nuno (2016), A financeirização do capitalismo em Portugal. Lisboa: Actual.

Rodrik, Dani (2017), "Populism and the Economics of Globalization”, CEPR Discussion Paper, n. ${ }^{\circ} 12119$.

Rosanvallon, Pierre (2016), "How to Create a Society of Equals: Overcoming Today's Crisis of Inequality”, Foreign Affairs, 95(1), 16-22.

Santos, Boaventura de Sousa (2014), Epistemologies of the South - Justice against Epistemicide. London: Paradigm Publishers.

Santos, Boaventura de Sousa (2017), "O problema do passado é não passar: nos cem anos da Revolução Russa”, Jornal de Letras, 1 de fevereiro, pp. 23-24.

Sapir, Jacques (2016), Souveraineté, démocratie, laïcité. Paris: Michalon.

Schmidt, Vivien; Thatcher, Marc (orgs.) (2013), Resilient Liberalism in Europe's Political Economy. Cambridge: Cambridge University Press.

Steger, Manfred; Roy, Ravi (2010), Neoliberalism: A Very Short Introduction. Oxford: Oxford University Press.

Stiglitz, Joseph (2002), Globalization and Its Discontents. New York: Norton.

Streeck, Wolfgang (2013), Tempo comprado. Lisboa: Actual.

Streeck, Wolfgang (2016), How Will Capitalism End? Essays on a Failing System. London: Verso.

Traverso, Enzo (2016), Left-Wing Melancholia: Marxism, History, and Memory. New York: Columbia University Press.

Williamson, John (1990), "What Washington Means by Policy Reform”, in John Williamson (org.), Latin American Adjustment: How Much Has Happened. Washington, D.C.: Institute for International Economics, 7-22.

Williamson, John (1993), "Democracy and the "Washington Consensus'”, World Development, 21(8), 1329-1336. DOI: 10.1016/0305-750X(93)90046-C.

Williamson, John (2004), “The Strange History of the Washington Consensus”, Journal of Post Keynesian Economics, 27(2), 195-206.

\section{João Rodrigues}

Faculdade de Economia da Universidade de Coimbra I Centro de Estudos Sociais da Universidade de Coimbra

Avenida Dias da Silva, 165, 3004-512, Coimbra, Portugal

Contacto: joaorodrigues@ces.uc.pt 


\section{In the Shadow of 1989: International Political Economy after the End of History}

This article argues that nearly three decades after 1989, a year marking the onset of wide-reaching global transformations, we still live under the shadow of one of its main consequences in terms of political economy: the fatal crisis of socialism implied that capitalism, whose neoliberal turn intensified, ceased to be subject to systemic checks and balances to its action. This diagnosis will be explored through the detailed analysis of two formulas and a document that appeared, perhaps not by chance, in 1989: the Washington Consensus, the end of history and the so-called Delors Report about the European Monetary Union. Seen together, they reflect some of the central planks of an international political economy of a neoliberal bent, still to be surpassed institutionally, due to the lack of fear among the power elites, among other factors. The article concludes by making a populist proposal to begin the process of reversing this perverse state of affairs.

Keywords: capitalism; European Union; neoliberalism; political economy; populism; socialism.

\section{À l'ombre de 1989: économie politique internationale après la fin de l'histoire}

Presque trois décennies après 1989 , nous soutenons que nous continuons à vivre à l'ombre d'une année durant laquelle se firent jour des transformations de portée mondiale: la crise fatale du socialisme a impliqué que le capitalisme, dont le penchant néolibéral s'est accentué, a cessé d'avoir des freins et des contrepoids systémiques. Nous exploiterons ce diagnostic par le biais de la scalpelisation de deux formules et d'un document, qui ne sont peut-être pas apparus par hasard, en 1989: le Consensus de Washington, la fin de l'histoire et le dénommé Rapport Delors sur l'Union Économique et Monétaire. Vus de façon articulée, ils sont bien le reflet de quelques-uns des éléments centraux d'une économie politique internationale, au caractère néolibéral, qui reste encore aujourd'hui à dépasser en termes institutionnels, en partie en raison de l'absence de crainte parmi les élites du pouvoir. Enfin, en guise de conclusion, nous suggérons une piste populiste pour le début d'un éventuel dépassement de ce pervers état de choses.

Mots-clés: capitalisme; économie politique; néolibéralisme; populisme; socialisme; Union européenne. 